\title{
Public health in undergraduate medical education
}

\author{
Arunodaya Barman
}

Professor, Faculty of Medicine, Universiti Sultan Zainal Abidin, Terengganu, Malaysia.

One of the principles of learning is that it is need-based. Medical graduates should learn relevant knowledge, skills and attitude that fulfill their need later in their professional life. A medical undergraduate student needs to mastery lot many things as contents of medical education is ever increasing. Contents which are not relevant in students' professional life fail to motivate them to engage during undergoing academic program.

The ultimate aim of medical education is to create opportunity for the students to acquire clinical competency after the completion of medical course. ${ }^{1}$ It was found that undergraduate medical students are interested above all in the diagnosis and treatment of diseases of individual patient; population-based health care is seldom regarded as important. ${ }^{2}$ There are arguments for and against the proposition that public health has to be adequately covered in the undergraduate medical course. Medical students in the present culture and set up of medical schools are so strongly motivated for clinical comptency, public health has limited importance to them. Against the proposition, it is argued that the effective medical practice needs an ability to think in terms of populations as well as individuals and hence public health needs to be considered as an important aspect of medical education. It is just a question how to deliver it to make as percieved need of students learning. ${ }^{3}$

The core content of medical curriculum consists of the fundamental theory and practice of clinical medicine; however, inclusion of basic biomedical, behavioural and social sciences, general clinical skills, clinical decision-making skills, communication abilities and medical ethics in the curriculum produce need-based and competent medical practitioners for the community. ${ }^{4}$ Public health was severely criticized by the students because they perceived that the subject was not very important and it was not relevant to clinical practice which medical graduates consider as the ultimate pillar of their success. After change of course contents in relation to public health and community orientation, the situation is reported to be improved in many medical schools. ${ }^{5}$ Teachers and policy makers should demonstrate the relevancy of public health issues to the clinical practice. ${ }^{5}$ Medical faculty should identify the ways to integrate basic biomedical sciences and public health to enhance understanding of scientific knowledge, concepts and methods necessary to improve standard of clinical sciences.

Integrated teaching and learning, which is one of the important components of a present day medical curriculum, may be a way to make public health relevant to clinical practice, especially for the students. 'The main aim of integrated public health teaching is to facilitate the students' acquisition of knowledge, skills and attitudes that promote the effective application of public health approaches to clinical practice'. ${ }^{2}$ It is important that public health should not be seen by the students as a compartmentalised content course .6,7 The medical curriculum should be relevant to the needs of time and should address community health problems. ${ }^{8}$ Some of the topics may need to be taken out of the present contents for which there are specialised personnel and departments, such as public health engineering. Integrated teaching and learning may be possible in hospital and community-based teaching. Community does not mean only the rural community, and can refer to the urban community too. All the resources in the hospital attached to the medical school and community settings should be utilized as learning resources in a need-based and community-oriented medical curriculum.

\section{References}

1. Ainsworth MA, Rogers LP, Markus JF, Dorsey NK, Blackwell TA, Petrusa ER. Standardized Patient Encounters. A Method for Teaching and Evaluation. JAMA 1991;266(10):1390-6.

2. Stone DH. Public health in the undergraduate medical curriculum - can we achieve integration? $J$ Eval Clin Pract 2000;6(1):9-14.

3. Woodward A. Public health has no place in undergraduate medical education. J Public Health Med 1994;16(4):389-92.

4. WFME Executive Council. Basic Medical Education WFME Global Standards for Quality Improvement. Copenhagen: World Federation for Medical Education, 2003.

5. Association of Faculties of Medicine of Canada (AFMC). An Environmental Scan of Best Practices in Public Health Undergraduate Medical Education. Report 3: Interviews with Canadian Medical School Representatives. Ottawa: AFMC, 2009.

6. GMC. Tomorrow's doctors. London: General Medical Council, 1993.

7. Dare AJ, Bullen C. Shifting perceptions and challenging the profession's paradigms: reflections from an undergraduate week of population health. New Zealand Med J 2008;121(1282):45-50.

8. Majumder MAA. A review of undergraduate medical curriculum in Bangladesh. Bangladesh Med J 2002;31:47-9.

Correspondence: Prof. Dr. Arunodaya Barman, Faculty of Medicine, Universiti Sultan Zainal Abidin, Kampus Perubatan, Jalan Sultan Mahmud, 20400 Kuala Teregganu, Terengganu, Malaysia. E-mail: arunodayabarman@yahoo.com.

South East Asia Journal of Public Health 2014;4(2):1 (C) 2014. Barman, publisher and licensee Public Health Foundation Bangladesh. This is an Open Access article which permits unrestricted non-commercial use, provided the original work is properly cited. DOI: http://dx.doi.org/10.3329/seajph.v4i2.23687 